\title{
The importance of keeping bile salts in their place
}

Bile contains several substances which are partially absorbed from the intestine and secreted again in the bile. They include urobilinogen, cholesterol, ${ }^{1}$ and possibly certain hormones ${ }^{2}$ and fat-soluble vitamins ${ }^{3}$. But the enterohepatic circulation of bile salts is unique in both its physiological importance and its efficiency.

Conjugated bile salts have powerful detergent properties, ${ }^{4}$ which are important in stabilizing the supersaturated state of bile and in promoting fat digestion and absorption. ${ }^{5}$ These functions, and the complex metabolism undergone by bile salts, all take place in the context of the enterohepatic circulation and depend on its proper functioning. The enterohepatie circulation may be thought of as an endless flow of detergent through the liver, biliary tract, small and to some extent large, intestine, and back to the liver again. Thanks to the gallbladder, this process occurs in bursts rather than continuously and it is estimated that the bile salt pool recirculates twice with each meal, or up to eight times a day. ${ }^{6}$ The normal pool size being 3 to $4 \mathrm{~g},{ }^{7}$ this means that about $24 \mathrm{~g}$ of bile salts enters the duodenum each day. A striking feature of the enterohepatic circulation is its efficiency as a closed recycling system. Probably more than $99 \%$ of the bile salts in the body are within the enterohepatic circulation at all times. The systemic blood contains less than $10 \mathrm{mg}$ in all $^{8}$ and none is detectable in the urine. ${ }^{9}$ A significant leak does occur into the stools, but the normal daily excretion of 15 to $20 \%$ of the pool represents a mere 3 to $4 \%$ escape at each turn of the cycle. ${ }^{10,} 11$

The efficiency of the enterohepatic circulation depends on several factors. First, the liver is avid in extracting bile salts from the blood. ${ }^{12}$ Isotope studies show the mean half-life of plasma cholic acid to he only 12.6 minutes. ${ }^{13}$ Such rapid clearance must be due to an active transport system, since it involves transfer of large polar molecules across the essentially lipid membrane of the liver cell. ${ }^{14}$ The same is true of biliary secretion which is also rapid. ${ }^{14}$ Labelled bile salt has been detected in the duodenum of a cholecystectomized patient within 20 minutes of intravenous injection. ${ }^{15}$ Secondly, having reached the duodenum, bile salts are prevented from regurgitating into the stomach by the competence of the pyloric sphincter. In normal subjects they are either undetectable or present in only trace amounts in the gastric juice. ${ }^{16}$ Thirdly, due to their low $\mathrm{pK}_{\mathrm{a}}$, conjugated bile acids exist mainly in the ionized form at the $p \mathrm{H}$ of the upper small intestinal lumen. ${ }^{4}$ This minimizes any tendency to diffuse down electrochemical gradients into the blood or lymph ${ }^{17}$ and ensures that the intraluminal concentration remains high until fat absorption is complete. ${ }^{18}$ This physicochemical 'seal' depends upon bile salts remaining in the conjugated state, since free bile acids readily diffuse out of the jejunal lumen. ${ }^{17}$ Deconjugation is within the capacity of many intestinal bacteria, ${ }^{19}$ so that a fourth factor in maintaining the efficiency of the enterohepatic circulation 
is the relative sterility of the small bowel contents. The mechanisms responsible for this probably include gastric acid, ${ }^{20}$ peristalsis, ${ }^{21}$ the immunoglobulins (especially $\operatorname{IgA}$ ) in gastrointestinal secretions ${ }^{22}$, and perhaps the antiseptic properties of bile itself. ${ }^{23}$

The last and most crucial factor is the process of intestinal reabsorption of bile salts. It is now well established that for this the essential requirement is an intact terminal ileum. ${ }^{24-29}$ This fact accords well with animal experiments showing that the distal quarter of the small intestine contains an active transport system for bile salt absorption. ${ }^{30}$ The importance of this system lies in the fact that once they pass into the colon bile salts are certain to be attacked and degraded by the abundant bacterial population. ${ }^{31} \mathrm{~A}$ small proportion may yet be absorbed ${ }^{32}$ and recirculated, but most is excreted in the faeces, much of it being strongly bound by particulate matter. ${ }^{33}$ In the face of these imminent hazards, one may perhaps view the retrieval activities of the terminal ileum as a case of natural brinkmanship. In this function the ileal transport system may be helped by the ileocaecal sphincter, which presumably delays the egress of ileal contents and also prevents reflux of the bacteria-rich caecal contents. ${ }^{34}$ In spite of these mechanisms the bile salt pool is depleted of up to $100 \mathrm{mg}$ per circulation, but this loss is readily made good by synthesis of new bile salt in the liver so that the size of the pool remains constant.

What is the purpose of such an efficient recycling system? Is it to preserve something precious or to enclose something that can be noxious? Conventionally, the enterohepatic circulation is regarded as an economy device which enables the organism to utilize a physiologically valuable agent many times. ${ }^{12,}{ }^{35}$ There are excellent grounds for accepting this view. If a bile salt pool of $4 \mathrm{~g}$ is to solubilize a dietary fat intake of up to $100 \mathrm{~g}$ per day, it must clearly be made available very many times each day. The only alternative, that the liver should repeatedly synthesize an entire new pool, can be discounted. The maximal synthetic capacity of the liver seems to be only about $3 \mathrm{~g}$ per day, or four times the normal daily turnover. ${ }^{27,} 36,37$

This limited reserve capacity for synthesis de novo must mean that any condition which interferes seriously with bile salt reabsorption will markedly reduce the quantity of bile salts entering the duodenum. This has been confirmed by ingenious experiments with Rhesus monkeys in which the enterohepatic circulation could be interrupted at will and by precisely graded amounts. ${ }^{38}$ It was found that recirculation defects of up to $20 \%$ were compensated for by increased hepatic synthesis, but with greater defects the output of bile salts fell progressively to about one-fifth of normal. There is a clinical counterpart to these experiments in the form of disease or resection of the terminal ileum. These disorders result in a serious defect of bile salt absorption, ${ }^{24-29}$ estimated by isotope studies to be such that more than $90 \%$ of the bile salt pool may be lost during the digestion of a single meal. ${ }^{39}$ Consequently, in ileectomy patients only 3 or $4 \mathrm{~g}$ of bile salts reaches the duodenum each day instead of the normal $24 \mathrm{~g} .{ }^{11}, 27$ These patients clearly have a detergent deficiency state and will presumably have difficulty with fat absorption. Intubation studies have in fact confirmed that duodenal bile salt concentrations are low during digestion, and have shown deficient incorporation of intraluminal lipid into the micellar phase of intestinal contents. ${ }^{25,29,40,41}$ These investigations explain the previously obscure fact of clinical experience that ileal resections cause more 
steatorrhoea than jejunal resections of comparable length. ${ }^{42}$ Detergent deficiency may also be a factor in the high incidence of gallstones in patients with terminal ileal disorders. ${ }^{43}$

These experimental and clinical facts show that efficient bile salt recirculation is necessary to ensure adequate supplies of solvent for fat absorption and bile stability, and confirm the view that the enterohepatic circulation is an important economy device.

An additional interpretation of the efficiency of the enterohepatic circulation is that it is designed to keep bile salts away from other parts of the organism in which they might be harmful. In other words, while a detergent is precious in the right place, it is also noxious in the wrong place. The evidence for this view consists of several clinical situations that have one common factorescape of bile salts from the narrow limits of their proper circuit.

First, there is the problem of bile salt catharsis or the overloaded colon syndrome. This again is a result of ileal disease. Normally the colon is presented with only a minute fraction of the circulating pool at each meal. Even a minor defect in ileal absorption will multiply this quantity many times and flood the colon with detergent. This is probably the main reason why watery diarrhoea occurs so often in patients with regional enteritis or after ileal surgery. ${ }^{44}$ Characteristically, this diarrhoea occurs after meals and it may be so profuse and urgent that the patient dare not leave his home. It is worst in the morning, when the bile salt pool is largest due to overnight accumulation of newly synthesized material. ${ }^{29}$ Steatorrhoea may be mild or absent, indicating that the recirculation defect is partial and compensated. The concept of bile salt catharsis rests on experiments showing that these substances strongly inhibit water and electrolyte absorption by the colon. ${ }^{45,}{ }^{46}$ There is clinical evidence also in that feeding the bile-salt-binding resin cholestyramine alleviates the diarrhoea, ${ }^{44,47}$ while feeding taurocholate worsens it. ${ }^{25}$ This distressing syndrome has been aptly named 'cholerhoeic enteropathy'. ${ }^{10}$

Conceivably, the same mechanism contributes to the diarrhoea associated with rapid small bowel transit, as in thyrotoxicosis, since experimentally speeding the passage of intestinal contents does reduce bile salt absorption. ${ }^{28}$ It has been suggested that even the small quantity of bile salts normally entering the colon acts physiologically to prevent undue dehydration of the faeces. ${ }^{45}$ If this is true, then the normal daily excretion of 700 to $800 \mathrm{mg}$ represents not a regrettable waste but a carefully regulated dosi of a natural purge, and minor increases in the colonic load might well cause diarrhoea.

An inevitable effect of the overloaded colon syndrome is increased bacterial production of bile acid metabolites, some of which are absorbed and give rise to high blood levels of free bile acids. ${ }^{48}$ The significance of this is uncertain, but if there were much absorption of lithocholic acid (the major metabolite of chenodeoxycholic acid) this could be relevant to the high incidence of gallstones in ileal disorders. ${ }^{43}$ In experimental animals feeding lithocholic acid has been found to induce cholelithiasis and also liver damage. ${ }^{49-51}$

In the stagnant loop syndrome, a disorder of the enterohepatic circulation occurs which is somewhat similar to that seen in ileal disease. Excessive bacterial degradation of bile salts occurs, but in the small intestine rather than the colon. ${ }^{52}$ In severe cases this results in local detergent deficiency right at the site of fat absorption. ${ }^{53} \mathrm{~A}$ further consequence is high local 
concentrations of free bile acids which may well be toxic to the small bowel mucosa, inhibiting absorption of nutrients such as sugars, ${ }^{54,55}$ amino acids $^{54,} 55$ and fatty acids, ${ }^{56}$ as well as of water and electrolytes. ${ }^{45}$ The toxicity of free bile acids may, however, be masked by adequate concentrations of conjugates, presumably through incorporation of the free acids into micelles. ${ }^{57}$ The enterohepatic circulation is likely to be abnormal in two contrasting ways. The first is excessive excretion of bacterially degraded bile acids, which continue past the 'safety net' of the terminal ileum either because they are bound by bacteria and other solid matter or possibly because they are too altered to be recognized by the transport system. Their effect on colonic, or indeed ileal, function may contribute to the diarrhoea of this condition, which would explain the finding that the diarrhoea is worsened by feeding taurocholate. ${ }^{53}$ On the other hand, bacterially deconjugated bile acids which remain in solution in the upper small bowel may, thanks to their relatively high $\mathrm{pK}_{\mathrm{a}},{ }^{4}$ diffuse out of the lumen before they reach the ileum. In severe cases, this transjejunal leakage could constitute the main mode of bile salt absorption. The extent to which absorption is preceded by deconjugation may be indicated by the serum concentration of free bile acids, which is sometimes very high. ${ }^{48}$ This in turn may be pathogenic as already noted.

A quite different abnormality of the enterohepatic circulation occurs in cholestasis and cirrhosis, namely, obstruction. In cholestasis, whether intrahepatic or extrahepatic, it is accepted that steatorrhoea and its complications such as osteomalacia are due to failure of bile salts to enter the small intestine. ${ }^{58,}{ }^{59}$ In cirrhosis too malabsorption is common, ${ }^{60}$ and recently it has been shown that this is associated with bile salt deficiency in the duodenum. ${ }^{61}$ This is probably not due merely to impaired bile salt synthesis by a damaged liver, since steatorrhoea often occurs in well compensated cirrhosis. Moreover, isotopic measurement of the body pool of cholic acid has shown it to be greater than normal in cirrhosis. ${ }^{13}$ The paradox may be resolved by postulating a defect in transport of bile salts into the biliary tract, due perhaps to failure of canaliculi in regeneration nodules to link up with the duct system. The result is a small pool of bile salts circulating enterohepatically in the normal way and another pool circulating uselessly in the systemic blood (with constant exchange between the two pools). This failure to keep bile salts in their place results in high serum levels, most of the increase being due to conjugated bile acids. ${ }^{62,}{ }^{63}$ Serum levels are particularly high in patients with cholestasis and are said to be responsible for pruritus ${ }^{64}$ (probably through deposition in the skin $^{65}$ ), bradycardia, ${ }^{23}$ and target cells in the circulating blood. ${ }^{66}$ It seems likely that other ill effects await discovery.

Finally, there are the diseases associated with the presence of bile salts in parts of the digestive system which are not used to dealing with detergents, namely, the stomach and pancreas. It was shown in 1888 that acute gastric ulcers can be induced in animals by feeding bile salts. ${ }^{67}$ Recently, it has been found that in patients with gastric ulcer the stomach contains on average far more bile salts than normal, ${ }^{16}$ presumably because of the high incidence of pyloric incompetence in these subjects. ${ }^{68}$ Cause and effect remain to be identified. However, Davenport ${ }^{69}$ has demonstrated that detergents, including bile salts, damage the gastric mucosal barrier and allow hydrogen ions to diffuse into the stomach wall. This aggressive action of bile salts out of their 
place may well explain the abnormally permeable mucosa of patients with gastric ulcer and atrophic gastritis. ${ }^{70}$ The resulting seepage of acid not only erodes the stomach wall but gives a false impression of hypochlorhydria. ${ }^{70}$ With pancreatitis the role of bile salts is controversial. ${ }^{71}$ Many believe that an important pathogenetic factor is reflux into the pancreatic duct of bile ${ }^{72}$ or bile-containing duodenal contents. ${ }^{73}$ Introduction of pure bile salt or other detergent solutions will induce necrosis in the dog's pancreas, ${ }^{74}$ possibly by activating phospholipase $A .^{75}$ This pancreatic enzyme converts biliary lecithin into lysolecithin, which is highly injurious to pancreatic tissue. ${ }^{75}$

In conclusion, it must also be considered whether over-efficient recycling of bile salts could be harmful. Too complete ileal absorption might well cause constipation ${ }^{45}$ but, in addition, it could have an important effect on cholesterol metabolism. Bile salt synthesis and excretion comprise the major route for cholesterol catabolism ${ }^{31}$ and are reduced in some patients with familial hypercholesterolaemia. ${ }^{76}$ In normal subjects, the factors controlling bile salt synthesis are incompletely understood but it can be assumed that, if faecal excretion is reduced for any reason, hepatic breakdown of cholesterol to bile salts will also be reduced and this might result in hypercholesterolaemia. The amount of bile salts excreted in the faeces is probably influenced by the nature of the diet. In animal experiments a low-residue diet is associated with reduced bile acid excretion, ${ }^{77}$ probably because of slow intestinal transit. ${ }^{78}$ In western countries the diet is typically low in bulk and vegetable fibre and constipation is common. ${ }^{79}$ Taking artificial bulk supplements increases faecal excretion of bile acids and significantly reduces the serum cholesterol, ${ }^{80}$ while a high intake of fruit and vegetables also lowers the serum cholesterol level. ${ }^{81}$ It is conceivable that the general tendency in western society for high serum cholesterol levels is related to the low bulk content of the diet, and that this effect is mediated, at least in part, by suboptimal bile salt excretion. Perhaps after all a mild, diet-related inefficiency of the enterohepatic circulation is desirable.

\section{K. W. HEATON \\ The Department of Medicine, Bristol Royal Infirmary}

\section{REFERENCES}

${ }^{1}$ Taylor, C. B., and Ho, K.-J. (1967). A review of human cholesterol metabolism. Arch. Path., 84, 3-14.

${ }^{2}$ Adlercreutz, H. (1965). Oestrogens in human bile. In The Biliary System, pp. 369-384. Edited by W. Taylor. Blackwell, Oxford.

'Rothman, M. M. (1965). In Gastroenterology, Edited by H. L. Bockus. 2nd ed., Vol. 3, p. 576. Saunders, Philadelphia.

'Hofmann, A. F., and Small, D. M. (1967). Detergent properties of bile salts: correlation with physiological function Ann. Rev. Med., 18, 333-376.

- (1965). Clinical implications of physicochemical studies on bile salts. Gastroenterology, 48, 484-494.

'Borgström, B., Dahlqvist, A., Lundh, G., and Sjövall, J. (1957). Studies of intestinal digestion and absorption in the human. J. clin. Invest., 36, 1521-1536.

'Lindstedt, S. (1957). The turnover of cholic acid in man. Acta physiol. scand., 40, 1-9.

'Sandberg, D. H., Sjövall, J., Sjövall, K., and Turner, D. A. (1965). Measurement of human serum bile acids by gas-liquid chromatography. J. Lipid Res., 6, 182-192.

'Haslewood, G. A. D. (1967). Bile Salts. Methuen, London.

${ }^{10} \mathrm{Hofmann}$, A. F. (1967). The syndrome of ileal disease and the broken enterohepatic circulation: cholerheic enteropathy. Gastroenterology, 52, 752-757.

${ }^{11}$ Heaton, K. W. (1968). The role of the distal small intestine in the enterohepatic circulation of the conjugated bile acids. M.D. Thesis, University of Cambridge.

${ }^{12}$ Josephson, B. (1941). The circulation of the bile acids in connection with their production, conjugation and excretion. Physiol. Rev., 21, 463-486.

${ }^{13}$ Blum, M., and Spritz, N. (1966). The metabolism of intravenously injected isotopic cholic acid in Laennec's cirrhosis. J. clin. Invest., 45, 187-193.

1'Sperber, I. (1959) Secretion of organic anions in the formation of urine and bile. Pharm. Rev., 11, 109-134. 
${ }^{15}$ Heaton, K. W. (1967). Unpublished observations.

${ }^{10}$ Rhodes, J., Barnardn, D. E., Phillips, S. F., Rovelstad, R. A., and Hofmann, A. F. (1968). Increased reflux of bile into the stomach in gastric ulcer (abstr.). Gut, 9, 737.

${ }^{17}$ Dietschy, J. M. (1968). Mechanisms for the intestinal absorption of bile acids. J. Lipid Res., 9, 297-309.

${ }^{18}$ Borgström, B., Lundh, G., and Hofmann, A. (1965). The site of absorption of conjugated bile salts in man. Gastroenterology, 45, 229-238.

${ }^{10} \mathrm{Hill}$, M. J., and Drasar, B. S. (1968). Degradation of bile salts by human intestinal bacteria. Gut, 9, 22-27.

${ }^{20} \mathrm{Gray}$, J. D. A., and Shiner, M. (1967). Influence of gastric $p \mathrm{H}$ on gastric and jejunal flora. Ibid., 8, 574-581.

"Dixon, J. M. S., and Paulley, J. W. (1963). Bacteriological and histological studies of the small intestine of rats treated with mecamylamine. Ibid., 4, 169-173.

${ }^{22}$ Plaut, A. G., and Keonil, P. (1969). Immunoglobulins in human small intestinal fluid. Gastroenterology, 56, 522-530.

${ }^{23}$ Sobotka, H. (1937). Physiological Chemistry of the Bile. Baillière Tindall and Cox, London.

"Austad, W. I., Lack, L., and Tyor, M. P. (1967). Importance of bile acids and of an intact distal small intestine for fat absorption. Gastroenterology, 52, 638-646.

${ }^{25} \mathrm{Hardison}$, W. G. M., and Rosenberg, I. H. (1967). Bile-salt deficiency in the steatorrhea following resection of the ileum and proximal colon. New Engl. J. Med., 277, 337-342.

26Stanley, M. M., and Nemchausky, B. (1967). Fecal $\mathbf{C}^{14}$-bile acid excretion in normal subjects and patients with steroid-wasting syndromes secondary to ileal dysfunction. J. Lab. clin. Med., 70, 627-639.

${ }^{27}$ Heaton, K. W., Austad, W. I., Lack, L., and Tyor, M. P. (1968). Enterohepatic circulation of C'4-labeled bile salts in disorders of the distal small bowel. Gastroenterology, 55, 5-16.

${ }^{28}$ Meihoff, W. E., and Kern, F. (1968). Bile salt malabsorption in regional ileitis, ileal resection and mannitolinduced diarrhea. J. clin. Invest., 47, 261-267.

${ }^{29}$ van Deest, B. W., Fordtran, J. S., Morawski, S. G., and Wilson, J. D. (1968). Bile salt and micellar fat concentration in proximal small bowel contents of ileectomy patients. J. clin. Invest. 47, 1314-1324.

${ }^{80}$ Lack L., and Weiner, I. M. (1961). In vitro absorption of bile salts by small intestine of rats and guinea-pigs. Amer. J. Physiol. 200, 313-317.

${ }^{31}$ Danielsson, H., and Tchen, T. T. (1968). Steroid metabolism. In Metabolic Pathways, Edited by D. M. Greenberg, 3rd ed., vol. 2, Lipids, Steroids and Carotenoids, pp. 117-168. Academic Press, New York.

${ }^{32}$ Samuel, P., Saypol, G. M., Meilman, E., Mosbach, E. H., and Chafizadeh, M. (1968). Absorption of bile acids from the large bowel in man. J. clin. Invest., 47, 2070-2078.

${ }^{33}$ Norman, A. (1964). Faecal excretion products of cholic acid in man. Brit. J. Nutr., 18, 173-186.

${ }^{34}$ Gorbach, S. L., Plaut, A. G., Nahas, L. Weinstein, L., Spanknebel, G., and Levitan, R. (1967). Studies of intestinal microflora. II. Microorganisms of the small intestine and their relations to oral and fecal flora. Gastroenterology, 53, 856-867.

${ }^{35}$ Lack, L., and Weiner, I. M. (1967). Role of the intestine during the enterohepatic circulation of bile salts. Ibid., 52, 282-287.

${ }^{38}$ Danielsson, H., Eneroth, P., Hellström, K., Lindstedt, S., and Sjövall, J. (1963). On the turnover and excretory products of cholic and chenodeoxycholic acids in man. J. biol. Chem., 238, 2299-2304.

${ }^{87}$ Carey, J. B., and Williams, G. (1969). Maximum primary bile salt synthesis rates in man (abstr.). Gastroenterology, 56,1249.

${ }^{88}$ Dowling, R. H., and Small, D. M. (1968). The effect of controlled interruptions of the enterohepatic circulation on the composition of bile in the Rhesus monkey (abstr.). J. clin. Invest., 47, 26a.

${ }^{89}$ Low-Beer, T. S., Lack, L., and Tyor, M. P. (1969). Effect of one meal on enterohepatic circulation of bile salts (abstr.). Gastroenterology, 56, 1179.

${ }^{\circ 0}$ Krone, C. L., Theodor, E., Sleisenger, M. H., and Jeffries, G. H. (1968). Studies on the pathogenesis of malabsorption. Lipid hydrolysis and micelle formation in the intestinal lumen. Medicine (Baltimore), 47, 89-106.

"McLeod, G. M., and Wiggins, H. S. (1968). Bile-salts in small intestinal contents after ileal resecton and in other malabsorption syndromes. Lancet, 1, 873-876.

${ }^{42}$ Kalser, M. H., Roth, J. L. A., Tumen, H., and Johnson, T. A. (1960). Relation of small bowel resection to nutrition in man. Gastroenterology, 38, 605-615.

${ }^{43}$ Heaton, K. W., and Read, A. E. (1969). Gallstones in patients with disorders of the terminal ileum and disturbed bile salt metabolism. Brit. med. J., 3, 494-496.

"Rowe, G. G. (1967). Control of tenesmus and diarrhea by cholestyramine administration. Gastroenterology, 53, 1006.

'5orth, W., Rummel, W., and Glasner, H. (1966). Zur resorptionshemmenden Wirkung von Gallensäuren. Naunyn-Schmiedebergs Arch. exp. Path. Pharmak., 254, 364-380.

"Mekhjian, H. S., Phillips, S. F., and Hofmann, A. F. (1968). Conjugated bile salts block water and electrolyte transport by the human colon (abstr.). Gastroenterology, 54, 1256.

"Poley, J. R., and Hofmann, A. F. (1968). Diarrhea following ileal resection: pathogenesis and treatment. (abstr). J. clin. Invest., 47, 79a-80a.

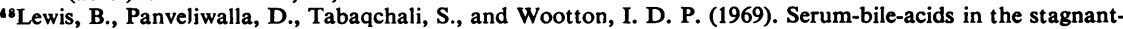
loop syndrome. Lancet, 1, 219-220.

"Palmer, R. H., and Hruban, Z. (1966). Production of bile duct hyerplasia and gallstones by lithocholic acid. J. clin. Invest., 45, 1255-1267.

${ }^{60} \mathrm{Carey}$, J. B., Wilson, I. D., Zaki, F. G., and Hanson, R. F. (1966). The metabolism of bile acids with special reference to liver injury. Medicine (Baltimore), 45, 461-470.

${ }^{51} \mathrm{Holsti}, \mathrm{P}$. (1960). Cirrhosis of the liver induced in rabbits by gastric instillation of 3-monohydroxycholanic acid. Nature (Lond.), 186, 250.

${ }^{52}$ Tabaqchali, S , and Booth, C C. (1966). Jejunal bactenology and bile-salt metabolism in patients with intestinal malabsorption. Lancet, 2, 12-15.

s3__, Hatzioannou, J., and Booth, C. C. (1968). Bile-salt deconjugation and steatorrhoea in patients with the stagnant-loop syndrome. Ibid., 2, 12-16.

s4Pope, J. L., Parkinson, T. M., and Olson, J. A. (1966). Action of bile salts on the metabolism and transport of water-soluble nutrients by perfused rat jejunum in vitro. Biochim. biophys. acta (Amst), 130, 218-232.

${ }^{8}$ Baraona, E., Palma, R., Navia, E., Salinas, A., Orrego, H., and Espinoza, J. (1968). The role of unconjugated bile salts in the malabsorption of glucose and tyrosine by everted sacs of jejunum of rats with the 'blind-loop syndrome'. Acta physiol., latinoam., 18, 291-297. 
${ }^{56}$ Dawson, A. M., and Isselbacher, K. J. (1960). Studies on lipid metabolism in the small intestine with observations on the role of bile salts. J. clin. Invest., 39, 730-740.

${ }^{57}$ Dietschy, J. M. (1967). Effect of bile salts on intermediate metabolism of the intestinal mucosa. Fed. Proc., 26, 1589-1598.

${ }^{38}$ Verzár, F., and McDougall, E. J. (1936). Absorption from the Intestine. Longmans, London.

${ }^{59}$ Atkinson, M., Nordin, B. E. C., and Sherlock, S. (1956). Malabsorption and bone disease in prolonged obstructive jaundice. Quart. J. Med., 25, 299-312.

${ }^{\circ}{ }^{\circ}$ Losowsky, M. S., and Walker, B. E. (1969). Liver disease and malabsorption. Gastroenterology, 56, 589-600.

"Badley, B. W. D., Murphy, G. M., Bouchier, I. A. D., and Sherlock, S. (1969). The role of bile salts in the steatorrhoea of chronic liver disease (abstr.). Ibid., 56, 1136.

${ }^{62}$ Rudman, D., and Kendall, F. E. (1957). Bile acid content of human serum. I. Serum bile acids in patients with hepatic disease. J. clin. Invest., 36, 530-537.

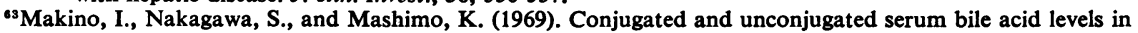
patients with hepatobiliary diseases. Gastroenterology, 56, 1033-1039.

"Datta, D. V., and Sherlock, S. (1963). Treatment of pruritus of obstructive jaundice with cholestyramine. Brit. med. J., 1, 216-219.

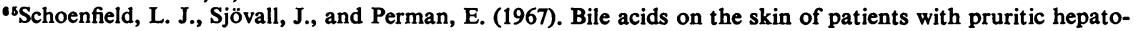
biliary disease. Nature (Lond.), 213, 93-94.

"Cooper, R. A., and Jandl, J. H. (1968). Bile salts and cholesterol in the pathogenesis of target cells in obstructive jaundice. J. clin. Invest., 47, 809-822.

${ }^{\circ}$ Rywosch, D. (1888). Vergleichende Versuche über die giftige Wirkung der Gallensauren. Arb. pharmak. Inst. Dorpat, 2, 102-140. Cited by Sobotka ${ }^{23}$, pp. 124, 130, 133, 138, 140.

${ }^{68}$ Kilby, J. (1966). Duodenal reflux and gastric secretion. (abstr.) Gut, 7, 710.

"Davenport, H. W. (1968). Destruction of the gastric mucosal barrier by detergents and urea. Gastroenterology, 54, $175-181$.

${ }^{70}$ Overholt, B. F., and Pollard, H. M. (1968). Acid diffusion into the human gastric mucosa. Ibid., 54, $182-189$.

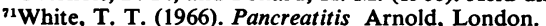

${ }^{29}$ Elliott, D. W., Williams, R. D., and Zollinger, R. M. (1957). Alterations in the pancreatic resistance to bile in the pathogenesis of acute pancreatitis. Ann. Surg., 146, 669-681.

${ }^{73} \mathrm{McCu}$ cheon, A. D. (1964). Reflux of duodenal contents in the pathogenesis of pancreatitis. Gut, 5, 260-265.

"Beck, I. T., Sum, P., and Bencosme, S. A. (1969). The study of the pathogeness of bile induced acute pancreatitis in the dog: experiments with detergents (abstr.). Gastroenterology, 56, 1247.

${ }^{75} \mathrm{Schmidt}, \mathrm{H}$., and Creutzfeldt, W. (1969). The possible role of phospholipase A in the pathogenesis of acute pancreatitis. Scand. J. Gastroent., 4, 39-48.

${ }^{70}$ Miettinen, T. A., Pelkonen, R., Nikkilä, E. A., and Heinonen, O. (1967). Low excretion of fecal bile acids in a family with hypercholesterolaemia. Acta med. scand., 182, 645-650.

${ }^{77}$ Portman, O. W. (1960). Nutritional influences on the metabolism of bile acids. Amer. J. clin. Nutr., 8, 462-470.

${ }^{78}$ Gustafsson, B. E., and Norman, A. (1969). Influence of the diet on the turnover of bile acids in germ-free and conventional rats. Brit. J. Nutr., 23, $429-442$.

${ }^{70}$ Cleave, T. L., Campbell, G. D., and Painter, N. S. (1969). Diabetes, Coronary Thrombosis and the Saccharine Disease, 2nd ed. Wright, Bristol.

${ }^{80}$ Forman, D. T., Garvin, J. E., Forestner, J. E., and Taylor, C. B. (1968). Increased excretion of fecal bile acids by an oral hydrophilic colloid. Proc. Soc. exp. Biol. (N.Y.), 127, 1060-1063.

${ }^{81}$ Anderson, J. T., Bhattacharyya, A. K., Grande, F., and Keys, A. (1968). A cholesterol-lowering diet (abstr.). Fed. Proc., 27, 221. 